\title{
Controls on carbohydrate compositions and pool sizes in Quaternary sediments of Lake Cadagno
}

\author{
NIROSHAN GAJENDRA ${ }^{1}$, JASMINE S BERG ${ }^{1}$, CARSTEN \\ JOHNNY SCHUBERT ${ }^{1,2}$, CLEMENS GLOMBITZA ${ }^{1}$ AND \\ MARK ALEXANDER LEVER ${ }^{1}$ \\ ${ }^{1}$ ETH Zurich \\ ${ }^{2}$ Eawag \\ Presenting Author: niroshan.gajendra@usys.ethz.ch
}

Carbohydrates represent a major fraction of the global sedimentary organic matter pool. However, little is known about sedimentary carbohydrate compositions and the factors that determine the long-term preservation of carbohydrates. Here we investigate the distribution and composition of carbohydrates across a 12,000-year sedimentary sequence from high-altitude (1923 m) alpine Lake Cadagno (Ticino, Switzerland). Over this period, the lake transitioned from glacial oxic holomictic (12.5 $\mathrm{kyr} \mathrm{BP})$ to euxinic $(12.1-9.8 \mathrm{kyr} \mathrm{BP})$ to finally meromictic conditions (since $9.8 \mathrm{kyr}$ BP)[1]. Besides reflecting this geochemical evolution, sediment layers contain distinct intercalations of autochthonous lacustrine, turbiditic, and/or terrestrial organic matter. The total organic carbon (TOC) content drops from $15 \%$ to below $5 \%$ of dry weight in the upper $20 \mathrm{~cm}$, implying intensive organic matter degradation in surface sediments. Carbohydrates, quantified as monomers with a new extraction method [2], make up most TOC at the lake-sediment interface. But carbohydrates decrease to values around $10 \%$ of TOC within the top $10 \mathrm{~cm}$, suggesting strong and selective degradation of carbohydrates within the first 200 years after deposition. Throughout the remainder of the meromictic and euxinic sediments, carbohydrates contents and fractions of TOC remain stable, indicating minimal degradation, before abruptly decreasing below $1 \%$ of TOC in the deep, oxidized glacial layers. In all sediment layers, carbohydrate monomers are consistently dominated by the neutral sugars galactose and glucose. Yet, compared to lacustrine layers, there are elevated proportions of amino sugars in glacial sediments, and of fucose, arabinose, and xylose in turbiditic deposits. This implies shifts in degradation selectivity with changing depositional regimes and/or carbohydrate sources, which we are currently investigating based on pyrolysis-GC/MS. Our study provides novel insights into carbohydrate pool sizes and compositions in lake sediments and improves the current understanding of the controls on carbohydrate preservation and degradation in the vast global sedimentary carbon sink.

[1] Wirth, S. B. et al. (2013), Geochimica et cosmochimica acta 120, 220-238.

[2] Zhu, R. et al. (2020), Organic Geochemistry 103963. 